\title{
Invasive Aspergillosis
}

\author{
Katelyn Gamson, $\mathrm{MD}^{7}$, Yile Ding, $\mathrm{MD}^{2}$, and Paul Aronowitz, $M D^{3}$ \\ 'Department of Internal Medicine, California Pacific Medical Center, San Francisco, CA, USA; ${ }^{2}$ Division of Hospital Medicine, University of California San \\ Francisco, San Francisco, CA, USA; ${ }^{3}$ Department of Internal Medicine, University of California Davis Medical Center, Davis, CA, USA.
}

KEY WORDS: aspergillus; aspergillosis; neutropenia; immunocompromised; fungal; pulmonary.

J Gen Intern Med 29(4):686-7

DOI: $10.1007 / \mathrm{s} 11606-013-2584-0$

(C) Society of General Internal Medicine 2013

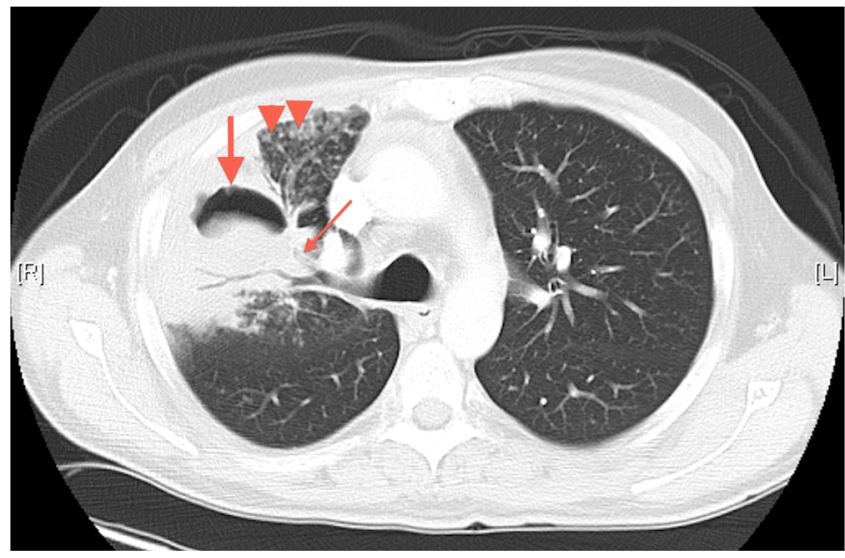

Figure 1. Computed tomography scan of the chest showing aircrescent sign (large arrow), tree-in-bud opacities (arrowheads), and communication of the cavitary lesion with the right upper lobe bronchus (small arrow).

\begin{abstract}
A 42-year-old man with acute lymphoblastic leukemia presented for consolidation chemotherapy. He had received induction chemotherapy one month previously, which had caused four weeks of neutropenia. On admission, he reported 1.5 weeks of a non-productive cough and night sweats, without fevers or chills. A chest radiograph revealed a cavitary right upper lobe lesion. Computed tomography scan of the chest showed consolidation in the right upper and middle lobes associated with central crescentic lucency ("air-crescent sign"; Fig. 1, large arrow), tree-in-bud opacities (Fig. 1, arrowheads), and communication of the cavitary lesion with the right upper lobe bronchus (Fig. 1, small arrow). Subsequent bronchoalveolar lavage polymerase chain reaction testing was positive for Aspergillus. The patient was treated with voriconazole and right upper and middle lobe resection. Gross pathology of the resected lung revealed a branch of the pulmonary artery abutting the
\end{abstract}

Received February 4, 2013

Revised May 17, 2013

Accepted August 6, 2013

Published online September 12, 2013

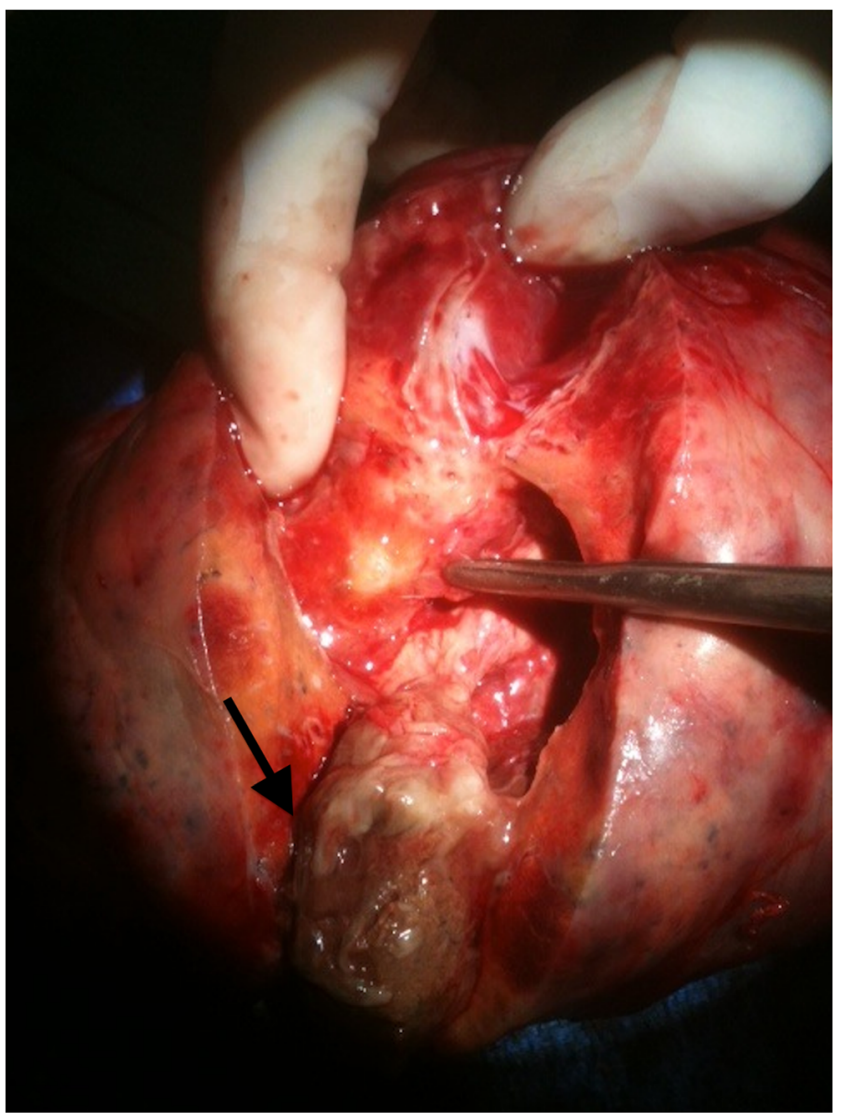

Figure 2. Gross pathology of resected lung showing the pulmonary artery abutting the cavity wall (forceps) and adjacent necrotic tissue (arrow).

cavity wall (Fig. 2, forceps), as well as necrotic tissue (Fig. 2, arrow). In invasive pulmonary aspergillosis (IPA), proximity to a great vessel is a relative indication for surgery. ${ }^{1}$ The prognosis of IPA is poor, with a mortality rate of $30-90 \%$. However, surgical resection may lower mortality, with one study showing a 30-day mortality of $10 \% .^{2}$ Our patient recovered without recurrence of fungal disease.

\section{Acknowledgments: \\ Contributors: None.}

Funders: None.

Prior presentations: Katelyn Gamson presented these images in a poster presentation at the American College of Physicians annual Northern California regional meeting on 17 November 2012. 
Conflict of Interest: The authors declare that they do not have a conflict of interest.

Corresponding Author: Katelyn Gamson, MD; Department of Internal Medicine, California Pacific Medical Center, 2351 Clay St., Suite 380, San Francisco, CA 94115, USA (e-mail: kgamson@gmail.com).

\section{REFERENCES}

1. Walsh TJ, Anaissie EJ, Denning DW, et al. Treatment of aspergillosis: clinical practice guidelines of the Infectious Diseases Society of America. Clin Infect Dis. 2008;46:327-60.

2. Matt $\mathbf{P}$, Bernet $\mathbf{F}$, Habicht $\mathbf{J}$, et al. Predicting outcome after lung resection for invasive pulmonary aspergillosis in patients with neutropenia. Chest. 2004; 126(6):1783-1788. 